\title{
ALCOHOL INTOXICATION \\ CONTRIBUTING TO MORTALITY IN BOHEMIAN WAXWINGS AND A PINE GROSBEAK
}

L.J. STEPHEN, 213 Macleod Avenue West, Dauphin, MB R7N OH4, and W. J. WALLEY, 222 Bossons Avenue, Dauphin, MB R7N OR2

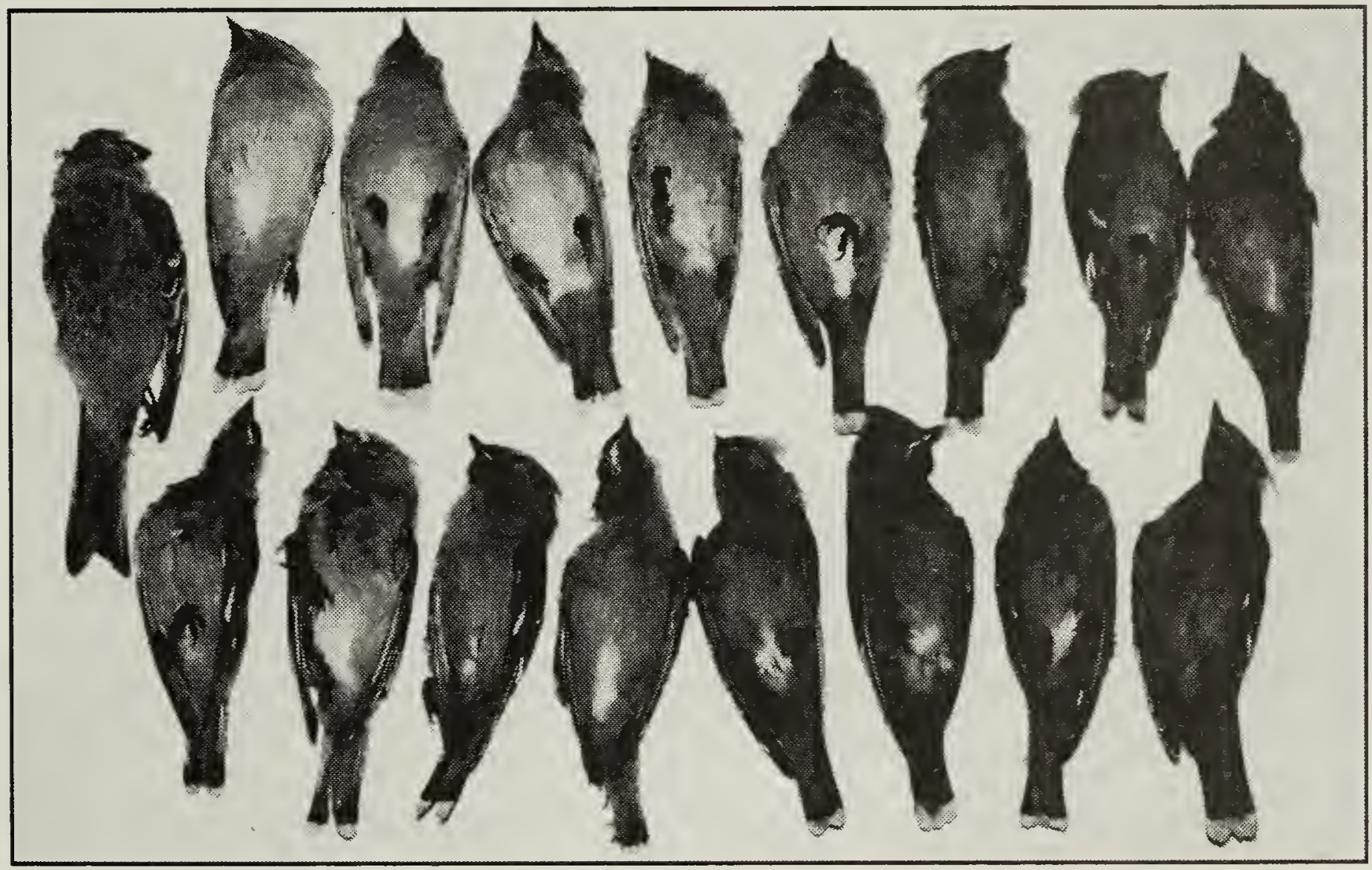

Fig. 1. 16 Bohemian Waxwings and 1 Pine Grosbeak, March 1974

W. J. Walley

On 23 and 24 March 1974, 16 Bohemian Waxwings and one immature male Pine Grosbeak (Fig. 1), were collected from the snow beneath the north-facing wall of the south wing of the Dauphin General Hospital. The birds had flown from a crab apple tree, $7.5 \mathrm{~m}$ north of the wing and $3 \mathrm{~m}$ east of the main building. This tree had a heavy crop of apples still hanging from the previous summer; because of warm weather, the odour emitted from these apples was strongly suggestive of fermentation.

According to the hospital patients, who heard and saw the birds crash into the windows and the intervening blue wall, most of the collisions had occurred in late morning and early afternoon. Blood on the windows and wall indicated where several birds had hit. Thirteen waxwings and the grosbeak were collected 23 March. Blinds were pulled over the windows, but another three waxwings perished similarly during the late afternoon of 24 March. No subsequent mortalities were detected, but by then most of the crab apples had been eaten or knocked from the tree.

Knowing that fermenting fruit can produce ethyl alcohol, we attempted to 
establish whether or not the birds were intoxicated.

\section{Methods:}

1. Gizzards were examined and the mash they contained was analysed for alcohol content.

\section{Blood was extracted from each bird's} heart with a clean syringe. Although only a few drops were obtained from each bird, the accumulated volume from all 17 birds totalled about $2 \mathrm{ml}$. This was sufficient for blood alcohol analysis performed by gas chromatography using the Poropak - Q - Column described by Kaufman (1973). ${ }^{3}$

\section{A necropsy was performed on each bird.}

\section{Results:}

1. Gizzards contained crab apple pulp, skin and core. Gizzard mash contained $3.1 \mathrm{~g}$ alcohol $/ 100 \mathrm{ml}$ mash. The grosbeak gizzard contained sunflower seeds and considerable grit in addition to crab apple pulp.

2. The merged blood alcohol level was $73 \mathrm{mg} / 100 \mathrm{ml}$. The pooled specimen from our 17 birds does not allow us to know blood alcohol levels of individual birds, nor the range of variation among individuals.

\section{The necropsy examinations showed} internal haemorrhage in all birds except one waxwing. The breasts had sustained the major impact, forcing the rib cage against the heart and rupturing major blood vessels. Massive clots were found around the major vessels as they entered or left the heart, and in the trachea. Therefore death was attributed to internal hemorrhage and /or asphyxia.

\section{Discussion:}

In humans, the clinical signs of alcohol intoxication are unusual when blood alcohol levels are below $50 \mathrm{mg}$ per $100 \mathrm{ml}$. On the other hand, operating a motor vehicle with blood alcohol in excess of $80 \mathrm{mg} / 100 \mathrm{ml}$ is illegal and can be an indictable offense.

Ours may be the only study that has attempted to measure blood alcohol levels in inebriated birds and to correlate them with aberrant coordination and flight performance. There have been two recent studies on the subject. Fitzgerald et al. studied two Cedar Waxwings that fell to the ground after ingestion of fermented hawthorn berries; their crop contents measured $380 \mathrm{ppm}$ and their livers, 238 and $989 \mathrm{ppm}$ of alcohol. ${ }^{2}$ (Levels from this study in ppm are: crab apple mash, $31,000 \mathrm{ppm}$, and merged blood alcohol level, $730 \mathrm{ppm}$ )

John V. Dennis listed 19 plant species said to cause apparent inebriation of birds." Mainly from newspapers, correspondence and word of mouth, he gleaned close to 30 instances of American Robin drunkenness; Cedar and Bohemian waxwings were "not far behind". He also mentions that waxwings are more prone to fly into windows when intoxicated.

It seems reasonable to speculate that ingestion of fermented crab apples and the resulting blood alcohol levels contributed to the aberrant behaviour and death of some or all of our waxwings. With a mean blood level of $73 \mathrm{mg} / 100 \mathrm{ml}$, one would expect that some individual waxwings had a blood level over $100 \mathrm{mg} / 100 \mathrm{ml}$.

In the 25 subsequent years, we have not been aware of further waxwing mortality near Dauphin, nor have we seen a recurrence of climatic conditions conducive to production of fermentation. 


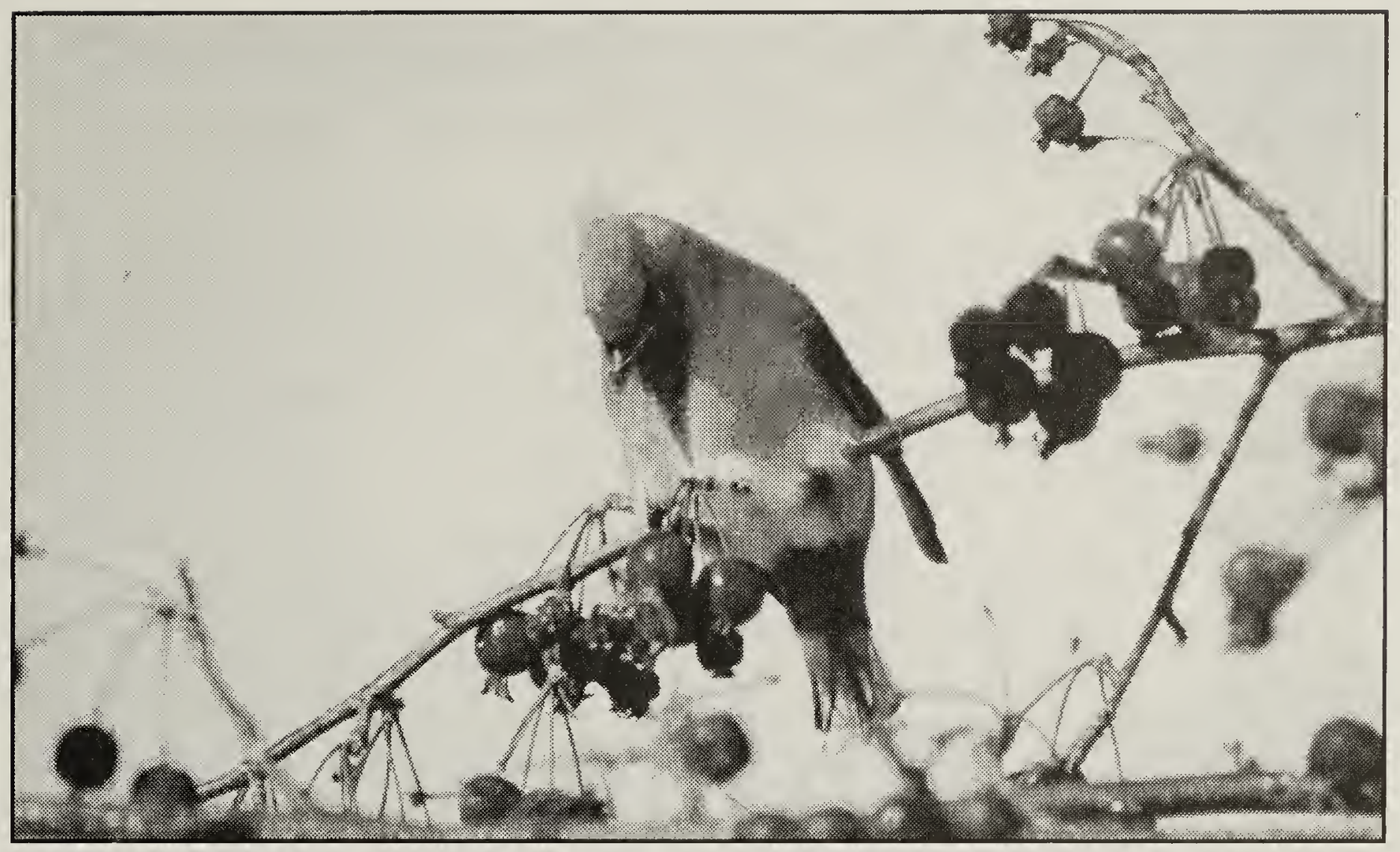

Bohemian Waxwing and crab apples

Ian Wilkie

\section{Acknowledgements:}

The authors herewith express gratitude to Stuart Houston and Robert Nero for reviewing the manuscript and offering constructive advice. We also thank David R.M. Hatch for his literature search and constructive comments. Gail White and Lloyd P. McCabe assisted in the alcohol determination.

1. Dennis, J. V. 1987. If you drink, don't fly: fermented fruit and sap can inebriate birds! Birder's World 1:15-19.
2. Fitzgerald, S. D., J. M. Sullivan, and R. J. Everson. 1990. Suspected ethanol toxicosis in two wild Cedar Waxwings. Avian Diseases 34:488-490.

3. Kaufman, J. H. 1973. A rapid screening procedure for drug and alcohol analysis in serum. American Journal of Medical Technology 39:338.

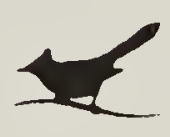

"Some of the days I've spent alone in the depths of the wilderness have shown me that immortal life beyond the grave is not essential to perfection, for these diverse days were so complete that there was no sense of time in them, they had no definite beginning or ending and formed a kind of terrestrial immortality." John Muir, In Nature's Heart : Wilderness Days of John Muir. 